\title{
An Orderly Untangling Model against Arching Effect in Emergency Evacuation Based on Equilibrium Partition of Crowd
}

\author{
Lianghai Jin, ${ }^{1,2}$ Mingzhang Xiang, ${ }^{1,2}$ Shu Chen, ${ }^{1,2}$ Xiazhong Zheng, \\ Ruojun Yao, ${ }^{3}$ and Yangao Chen ${ }^{4}$ \\ ${ }^{1}$ Hubei Key Laboratory of Construction and Management in Hydropower Engineering, Yichang, Hubei 443002, China \\ ${ }^{2}$ College of Hydraulic \& Environmental Engineering, China Three Gorges University, Yichang, Hubei 443002, China \\ ${ }^{3}$ China Institute of Water Resources and Hydropower Research, Beijing 100038, China \\ ${ }^{4}$ Sinohydro Bureau 7 Co., Ltd., Chengdu, Sichuan 610081, China
}

Correspondence should be addressed to Lianghai Jin; 16405495@qq.com

Received 19 March 2017; Revised 2 September 2017; Accepted 17 September 2017; Published 15 November 2017

Academic Editor: Cengiz Çinar

Copyright (C) 2017 Lianghai Jin et al. This is an open access article distributed under the Creative Commons Attribution License, which permits unrestricted use, distribution, and reproduction in any medium, provided the original work is properly cited.

\begin{abstract}
To untangle the arching effect of a crowd as much as possible in emergency evacuations, we employ a theoretical model of equilibrium partition of crowd batch. Based on the shortest time arrangement of evacuation, the crowd is divided into appropriate batches according to the occupied time of evacuation channel in order to determine the occupant number of every evacuation passageway. The number of each batch crowd is calculated under the condition that the time of entering the evacuation passageway is equal to the time of crossing over the evacuation passageway. Subsequently, the shortest processing time (SPT) rule establishes the evacuation order of each batch. Taking a canteen of China Three Gorges University as a background, we obtain the waiting time from the first person to the last one entering the evacuation channel in every batch by simulation. This research utilizes data from simulations to observe an untangling process against the arching effect based on the SPT rule. More specifically, evacuation time only lasts for $180.1 \mathrm{~s}$ in order and is $1.6 \mathrm{~s}$ longer than that in disorder, but the arching effect disappears. Policy recommendations are offered to improve the evacuation scheme in disaster operations.
\end{abstract}

\section{Introduction}

When a large number of people out of control swarm into an evacuation passageway, they will be firmly stuck in there and will bring about an arching effect. The arching effect is produced frequently in emergency evacuations. Due to the arching effect, crowd evacuation fails now and then. In 1994, an art show at the Karamay oil field in China caused a fire to form an arch of 800 students in the evacuation exit due to the poor evacuation strategy, and eventually 323 people died in the blaze. The arching effect in emergency evacuations is a problem that cannot be fenced all the time during the researching process of emergency management [1]. Therefore, untangling the arching effect is of great significance for crowd evacuation safety and reducing the occurrence of secondary disasters such as trampling.

Up to now, many mathematical models have been developed to simulate the pedestrian evacuation process inside buildings. Classically, these models can be categorized into two types: continuous and discrete. The social force model [2-4] is widely used as a representatively continuous model, in which the interactions between occupants and various environmental stimuli are quantified as force. The representatives of the discrete models are a cellular automaton model [5] and a lattice gas model [6]. These models after calibration can usually obtain satisfactory simulation results and are able to reproduce various behaviors and self-organization phenomena, such as the "herding" behavior [7], arching effect [8], and "faster-is-lower" phenomena [9]. For the discrete models, the representatives are cellular automaton and lattice gas models.

Existing evacuation models have achieved effective analysis of personnel micromovement or the overall macrotraffic situation during evacuation. However, in the real story of emergency, people are affected invariably by individual or group psychology, so their behavioral reactions which can 
cause many uncertainties are quite different from nonemergency [10, 11]. Hoogendoorn and Bovy [10] stated that individual behavior was affected by external factors, such as environmental stimuli and obstructions, and by internal factors, such as pedestrian intention and time constraints. Sime [11] presented an analytical model of pedestrian evacuation time, in which the impact of multiple factors, such as pedestrian psychology, building structures, and evacuation facilities, on pedestrian route choice behavior was considered. Fridolf et al. [12] provided a review on previously reported fire accidents in underground transport systems in addition to evaluating four different human behavior theories that could be used in fire safety design of railway stations. Apart from the issues mentioned above, evacuation speed and counterflow studies were also given much attention $[13,14]$. A study where the actual experiment was conducted with pedestrian counter flow was presented by Isobe et al. [15], who clarified the characteristic properties of pedestrian channel flow and showed the simulation model representing the counter flow. Cłapa et al. $[16,17]$ showed that the people density confirmed the dependency between the flow density of evacuating people and the speed of moving people. This dependency was proportional; the speed of people movement rose when the people density decreased. Stoppage of evacuating people was caused by the willingness to pass through the rescue teams as quickly as possible.

In this paper, we have developed an evacuation strategy for solving the arching phenomenon. With the Queuing Theory, quantitative analysis is conducted for the batching of a crowd. We put forward an equal of the time of entering an evacuation passageway and the time of crossing over an evacuation passageway to divide the crowd into reasonable batches and to determine crowd evacuation order on the basis of ordering rule SPT. We attempt to verify whether the arching effect will disappear within the security evacuation time.

\section{Method}

2.1. Orderly Partition Evacuation. In general evacuation, all pedestrians flock to the exit at the same time and the evacuation capacity of the passageway becomes unable to hold that load, so pedestrians get firmly stuck in the passageway. The longer the congestion time, the greater the risk of trampling.

In the partition evacuation process, the crowd is divided into several parts and the congestion time is changed into waiting time for relieving potential hazards. When the crowd evacuation starts, the batch of pedestrians closest to the exit start to escape from the disaster scene at first and the rest of the batches of people need to stay where they are. All batches of pedestrians evacuate one by one. Thus stated, we determine whether the orderly partition evacuation is feasible under critical conditions where the arching phenomenon disappears and there is not much difference between the orderly partition evacuation time and disorderly evacuation time. And the orderly partition evacuation time is within standard time.

\subsection{Calculation of Parameters}

2.2.1. Basic Parameters. The evacuation time depends on the escape speed. Therefore, we should make sure of the velocity initially. Generally, a single pedestrian's evacuation speed is affected by his/her own physical conditions and construction environment factors, and the occupants density is a critical factor for crowd evacuation speed. As usual, the crowd evacuation parameters include horizontal movement velocity, stair movement velocity, and flow coefficient [18].

(1) Horizontal Movement Velocity. The escape speed will not be affected and the initial speed will stay the same when the population density is small. However, the relation between velocity and density is represented by an increasing linear function when the density is greater than 0.55 pers $/ \mathrm{m}^{2}$. The concrete formula is shown as follows:

$$
\begin{aligned}
& V_{f}(D) \\
& = \begin{cases}V_{0}, & D<0.55 \mathrm{pers} / \mathrm{m}^{2} \\
\max \left[V_{f \min }, 1.4(1-0.226 D)\right], & D \geq 0.55 \mathrm{pers} / \mathrm{m}^{2},\end{cases}
\end{aligned}
$$

where $D$ is the crowd density, $V_{0}$ is walking velocity in different buildings when the population density is less than 0.55 pers $/ \mathrm{m}^{2}$, and $V_{f \min }$ is the minimum velocity in different environments.

(2) Movement Velocity on Stairs. The type of stair treads is a major factor affecting the evacuation speed. Stair treads include tread length and height. In formula (1), the influence parameter of horizontal movement is 1.4. Through the actual observation and data statistics, the influence parameter of stairs movement is $0.86(G / R)^{0.5}$. The formula is shown as follows:

$$
V_{f t}=0.86\left(\frac{G}{R}\right)^{0.5}(1-0.226 D),
$$

where $G$ is tread length and $R$ is tread height.

(3) Unit Outflow Coefficient. Egress capacity (flow rate) is expressed in persons per minute per unit width and represented by the product of density and velocity, shown as follows:

$$
f_{s}=K D(1-0.226 D)
$$

where $K$ takes 1.4 in horizontal channel and takes $0.86(G /$ $R)^{0.5}$ in stairs.

2.2.2. Partition Parameters. According to Section 2.1, the two most important parameters are the number of pedestrians in each batch and the waiting time of each batch among the orderly partition evacuation. We tend to regard the partition evacuation system as a queuing system for more easily analyzing the relations among the evacuation parameters. In this queuing system, the input procedure is deterministic and is composed of waiting and walking behavior of each part. The service regulation is first in first out (FIFO) and the time 
TABLE 1: Queue system of the crowd evacuation.

\begin{tabular}{lc}
\hline & Evacuation model \\
\hline Input rule & Deterministic type \\
Pass way & Multichannel \\
Cross rule & First in first out \\
\hline
\end{tabular}

taken by each batch of people through the passageway is service time. Thus stated, the corresponding queuing model is shown in Table 1.

In the event of disaster, the arching effect does not occur under the critical condition that the average cross time is equal to the average preparatory evacuation time when the crowd flocks to bottlenecks such as an escape staircase or evacuation passageway; the critical condition is defined as follows:

$$
T_{d}=T_{f}
$$

where $T_{f}$ is the average cross time and $T_{d}$ is the average preparatory evacuation time. The average cross time is the time during which the crowd crosses the evacuation passageway (stairs, corridors, etc.) and is defined as follows:

$$
T_{f}=\frac{L}{V},
$$

where $L$ is the length of the evacuation passageway and $V$ is obtained by (1) and (2).

The average preparatory evacuation time is the total number of evacuation occupants divided by the number entering the evacuation passageway per unit time, which is defined as follows:

$$
T_{d}=\frac{M}{f_{s} B},
$$

where $M$ is the total number of evacuation occupants, $f_{s}$ is the evacuation passageway unit flow coefficient, and $B$ is the effective width of entering the evacuation passageway corridor or door.

Considering multiple evacuation routes [19], the total crowd evacuation time can be the shortest under the condition that the holding time of each evacuation passageway is the same (to avoid the phenomenon of the evacuation passageway appearing as idle). Therefore, the number of evacuating people for each alleyway is obtained by the following equilibrium equation:

$$
\begin{aligned}
& \sum N_{j}=N_{T} \\
& \frac{N_{1}}{f_{s 1} B_{1}}=\frac{N_{2}}{f_{s 2} B_{2}}=\cdots=\frac{N_{j}}{f_{s j} B_{j}},
\end{aligned}
$$

where $N_{T}$ is the total number, $N_{j}$ is the number of evacuating people by $j$ th export, $f_{s j}$ is the unit outflow coefficient of $j$ th export, and $B_{j}$ is the effective width of $j$ th export.

To avoid the arching effect, the crowd partition model is adopted after the crowd evacuation direction is determined by the equilibrium equation (7). In order to figure out the number of each batch for single export, we divide the balanced evacuation numbers for each export and combine them with the critical condition (4), as follows:

$$
N_{j}=\sum M_{i j}=\sum\left(\frac{L}{V}\right) f_{s j} B_{j},
$$

where $M_{i j}$ is the number of each batch of $j$ th export.

When one batch's occupants escape from the disaster scene, the rest of the batches' occupants need to stay where they are. The waiting time is obtained in accordance with the condition that each batch of occupants escapes end-to-end.

When the crowd flows, the population density changes in pace with the surrounding environment variety. Therefore, the evacuation time can be calculated quantitatively unless we know the people's density in the evacuation passageway. However, we can solve this problem with the aid of virtual simulation. Simulation of evacuation in batches can obtain the time of the first man and last man entering the evacuation passageway of the $i$ th batch. The waiting time of each batch is calculated as follows:

$$
\begin{array}{r}
W_{i}=T_{(i-1)}^{1}-T^{0}{ }_{i}+W_{(i-1)} \\
\qquad\left(W_{0}=0, i=1,2,3, \ldots, m\right),
\end{array}
$$

where $T^{0}{ }_{i}$ is the time of the first person entering the passageway of the $i$ th batch, $T^{1}{ }_{i}$ is the time of the last person entering the passageway of the $i$ th batch, and $W_{i}$ is the waiting time of the ith batch.

2.3. The Evacuation Order. The evacuation order of each batch crowd can be seen as a single channel scheduling problem, as follows:

$$
1 \| \sum w_{i} C_{i}
$$

where $C_{i}$ is the finish time of evacuation of the $i$ th batch and $w_{i}$ is the weight of the $i$ th batch.

For the single channel scheduling problem, applying WSPT (weighted shortest processing time first) can get the optimal evacuation order. In particular, the WSPT rule transforms into SPT rule (shortest processing time first) with the case that each batch is weighted equally.

Because each batch is weighted equally when the crowd evacuates, we should employ the SPT rule to obtain the evacuation order of each batch. Accordingly, each batch of occupants begins to evacuate with the order based on the evacuation time of each batch, from short to long.

\section{Case Analysis}

3.1. The Basic Data and the Crowd Division. For the sake of convenience, we set XinYuan canteen of China Three Gorges University as the physical background, which is a building with 2 storeys. We suppose that the dining room is saturated and every seat is occupied. The capacity of the canteen is 1200 diners and each layer can accommodate 600 . Four seats are posted to stand by a table. Each table in this canteen has $0.6 \mathrm{~m}$ right-and-left clearance and $1.2 \mathrm{~m}$ fore-and-aft clearance from 


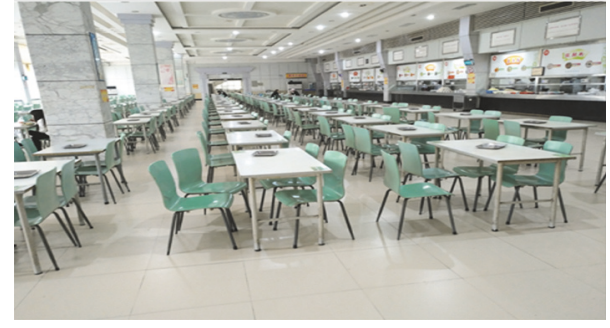

FIGURE 1: Collocation of dining room.

the next. There are two 2.7-meter-width doors at both sides of the dining room, and occupants can reach the evacuation stairs through the door. The effective width of the left-hand and right-hand evacuation stairs is, respectively, $2.1 \mathrm{~m}$ and $2.57 \mathrm{~m}$. Both sides of the stairs' pedal have identical flight run and flight raise, which are, respectively, $0.4 \mathrm{~m}$ and $0.17 \mathrm{~m}$. The real scene is shown in Figure 1.

In order to ensure the full use of the evacuation passageway, evacuation should be finished at the same time on both side stairs without leisure of the evacuation passageway. Due to the fact that the flight run and flight raise of both side stairs are the same, the effective egress capacity on both sides is equal. Effective egress capacity is proportional to the width of the stairs, and first division serves to obtain the number of each side's people according to the equilibrium equation (7) as follows:

$$
\begin{aligned}
\frac{N_{L}}{2.1} & =\frac{N_{R}}{2.57} \\
N_{L}+N_{R} & =600 .
\end{aligned}
$$

According to (11), the number $N_{L}$ of people evacuating through the left stairs is 268 (on the left side of the area in Figure 2), and the number $N_{R}$ of those evacuating through the right stairs is 332 (on the right side of the area in Figure 2).

After the first division, we partition the right-hand people to let the crowd line up in batches. In order to avoid the arching effect at the entrance of the evacuation passageway, the average passing rate has to be equal to the average preparatory evacuation rate.

The total length of the right side evacuation stairs is $11.4 \mathrm{~m}$, and the length of the middle platform is $2.6 \mathrm{~m}$. By actual observation, the density is 2.4 persons $/ \mathrm{m}^{2}$ when the crowd passes through the evacuation stairs. As a result, the movement speed on the stairs turns out to be $0.6 \mathrm{~m} / \mathrm{s}$ according to (2). According to (3), we further calculate a unit flow coefficient of $1.45 /(\mathrm{m} \cdot \mathrm{s})$ in the evacuation passageway. The movement speed of walking on the middle platform can also be seen as $0.6 \mathrm{~m} / \mathrm{s}$ owing to the short platform. The number of each batch of the right side is as follows:

$$
M_{R}=\left[\frac{d_{R}^{S}+d_{R}^{P}}{V_{f t}}\right] f_{s} B_{R}=87 .
$$

The right-hand crowd is divided into 87 occupants per batch. 332 people egress through the right stairs; the first three batches comprise 87 occupants; the last batch is 71 ; the batch
TABLE 2: Number of persons per batch on the right side.

\begin{tabular}{lc}
\hline Mark & Number/occupants \\
\hline$M_{R 1}$ & 87 \\
$M_{R 2}$ & 87 \\
$M_{R 3}$ & 87 \\
$M_{R 4}$ & 71 \\
\hline
\end{tabular}

TABLE 3: Number of persons per batch on the left side.

\begin{tabular}{lc}
\hline Mark & Number/occupants \\
\hline$M_{L 1}$ & 76 \\
$M_{L 2}$ & 76 \\
$M_{L 3}$ & 76 \\
$M_{L 4}$ & 40 \\
\hline
\end{tabular}

is marked as $M_{R i}(i=1,2,3,4)$, as shown in Figure 2 and Table 2.

The left-hand people are divided in the same way as follows:

$$
M_{L}=\left[\frac{d_{L}^{S}+d_{L}^{P}}{V_{f t}}\right] f_{s} B_{L}=76
$$

where $d_{L}^{S}$ is the length of stairs on the left side, $d_{L}^{P}$ is the length of the platform in the middle on the left side, and $B_{L}$ is the effective width of stairs on the left side.

When the crowd on the left side is divided into 76 persons per batch under the premise of (4), 268 people will need to be evacuated on the left side; the volume of the first three batches is 76 persons/batch; the last only has 40 persons; four batches are set as $M_{L i}(i=1,2,3,4)$, as shown in Figure 2 and Table 3.

3.2. Waiting Time and Queuing Sequence. Time of the first and last man starting to enter the stairs is obtained by simulation, and the waiting time of each batch is obtained from (9). The results are shown in Table 4.

Based on the SPT rule and data in Table 4, the evacuation order is as follows:

$$
\begin{aligned}
& \text { On the left side: } M_{L 1} \rightarrow M_{L 2} \rightarrow M_{L 3} \rightarrow M_{L 4} . \\
& \text { On the right side: } M_{R 1} \rightarrow M_{R 2} \rightarrow M_{R 3} \rightarrow M_{R 4} .
\end{aligned}
$$

3.3. Evacuation Simulation. The simulation is conducted using the above data that includes basic parameters, such as the occupant load of the facility, the characteristics of the population (e.g., shoulder breadth), the speed of movement, the waiting time, and the evacuation direction of each batch.

The above analysis of batch partition and orderly evacuation for the occupants only serves for the second layer. First of all, we should discuss the problem of whether the first layer should be analyzed. This question remains whether the evacuation time of the second floor is equal to the evacuation time of the whole building. For the disorderly state with no interval time, the simulation result is shown in Table 5.

The evacuation time of the second floor is $179.5 \mathrm{~s}$, and that of the whole building is $179.3 \mathrm{~s}$. Obviously, the error 


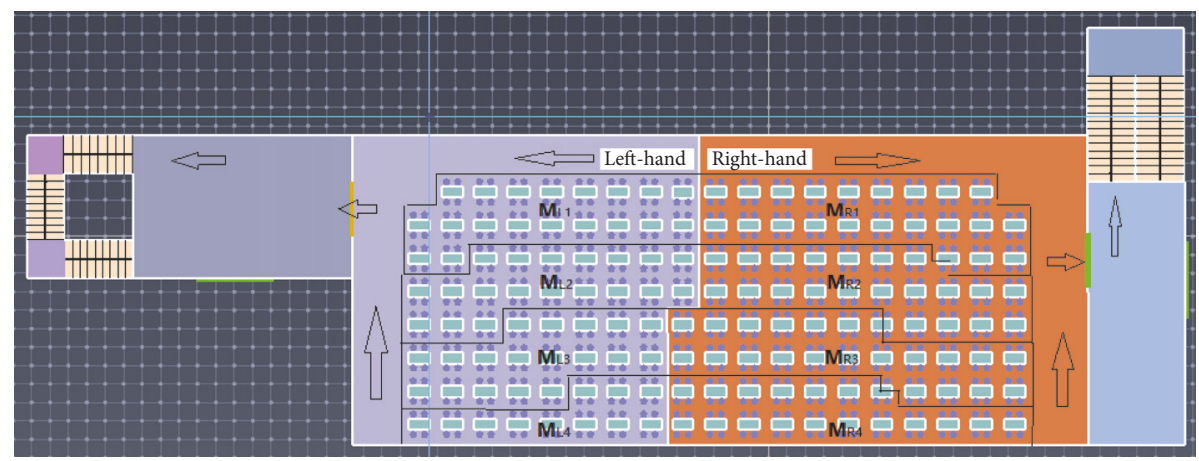

FIgURE 2: Crowd in batches.

TABLE 4: Waiting time of each crowd in line.

\begin{tabular}{lccc}
\hline Batch & $T^{0} / \mathrm{s}$ & $T^{1} / \mathrm{s}$ & $W_{i}=T_{(i-1)}^{1}-T_{i}^{0}+W_{(i-1)} / \mathrm{s}$ \\
\hline$M_{L 1}$ & 12.9 & 49.0 & 0.0 \\
$M_{L 2}$ & 14.0 & 50.9 & 35.0 \\
$M_{L 3}$ & 16.1 & 53.8 & 69.8 \\
$M_{L 4}$ & 18.6 & 54.5 & 95.0 \\
$M_{R 1}$ & 7.3 & 41.1 & 0.0 \\
$M_{R 2}$ & 8.6 & 41.8 & 34.5 \\
$M_{R 3}$ & 10.5 & 50.5 & 65.8 \\
$M_{R 4}$ & 11.5 & 53.7 & 104.8 \\
\hline
\end{tabular}

TABLE 5: The time comparison between the whole building and the second floor.

\begin{tabular}{lc}
\hline Situation & Evacuation time (s) \\
\hline The whole building & 179.3 \\
The second floor & 179.5 \\
\hline
\end{tabular}

TABLE 6: The evacuation time comparison.

\begin{tabular}{lc}
\hline Simulation & Time (s) \\
\hline Orderly evacuation & 181.1 \\
Disorderly evacuation & 179.5 \\
\hline
\end{tabular}

is caused by computer performances and program settings, and its relative value is $0.11 \%$ and can be ignored. Therefore, the second floor is determined as a key evacuation layer, which controls the emergency evacuation time of the whole building. From the simulation results, the evacuation process of the first layer does not exhibit the arching effect. As a result, it is only necessary to establish the orderly evacuation strategy for the crowd on the second floor.

By comparing the orderly evacuation time and the disorderly evacuation time, the simulation results are shown in Table 6.

Informed by Table 4 , the orderly evacuation time of the crowd after partial division is $1.6 \mathrm{~s}$ more than the disorderly evacuation time. From Figure 3(a), we can clearly see that the occupant variation at the right-hand passageway entrance is wavy under the orderly evacuation and the maximum value of variation is 27 people. Figure 3(b) shows that the variation under the disorderly evacuation is trapezoidal, the number of people is more than 30 during $20 \sim 120 \mathrm{~s}$, and the number even remains at about 60 during $50 \sim 110 \mathrm{~s}$. This is much greater than the maximum value of orderly evacuation.

Simulation results indicate that (1) the arching effect is serious under the disorderly evacuation situation; (2) the maximum radius of the crowd arch is 7 meters; (3) the maximum density is $4 \mathrm{occs} / \mathrm{m}^{2}$. However, when the crowd escapes in the queue of orderly evacuation, the arching effect of the crowd does not appear at the stairs' entrance as shown in Figure 4.

The critical density for accidents involving trampling is approximately $5 \mathrm{occs} / \mathrm{m}^{2}$ [20]. However, these critical figures are very variable and depend strongly on the physical characteristics of the pedestrians involved. Thus, even though the maximum density in simulation is less than the critical density for trampling, the possibility of trampling still remains high.

According to Hong Kong's Guidelines on Formulation of Fire Safety Requirements for New Railway Infrastructures (HK Fire Services Dept., 2013), there shall be adequate means of escape for all calculated populations under the worst-case scenario, to escape safely from the fire scene to an adjacent place of Safe Passage within 4.5 minutes without being overwhelmed by the effects of fire and smoke [21]. As a result, $181.1 \mathrm{~s}$ is less than the lowest requirement of 4.5 minutes.

\section{Conclusions}

We have developed a strategy for solving the arching effect. Therein, the evacuation balanced equation is based on the principle that the occupation time of each evacuation exit is equal. We divided the occupants firstly with consideration of the width of the evacuation passageway. Based on the Queuing Theory, the crowd was divided into batches according to the situation where the time of entering the evacuation passageway is equal to the time of crossing over an evacuation passageway. Then, a simulation program served to calculate the waiting time of each batch in accordance with the time from the first person to the last one entering the evacuation passageway. After that, the SPT rule determined the evacuation sequence of each batch after partitioning.

After simulations, we found that the arching effect disappears although the orderly evacuation does not make a 


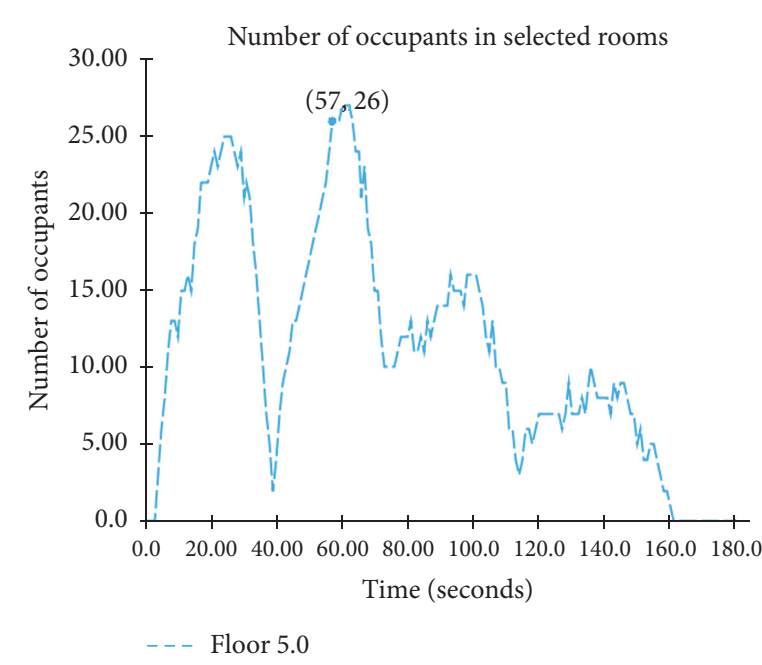

(a) Orderly evacuation

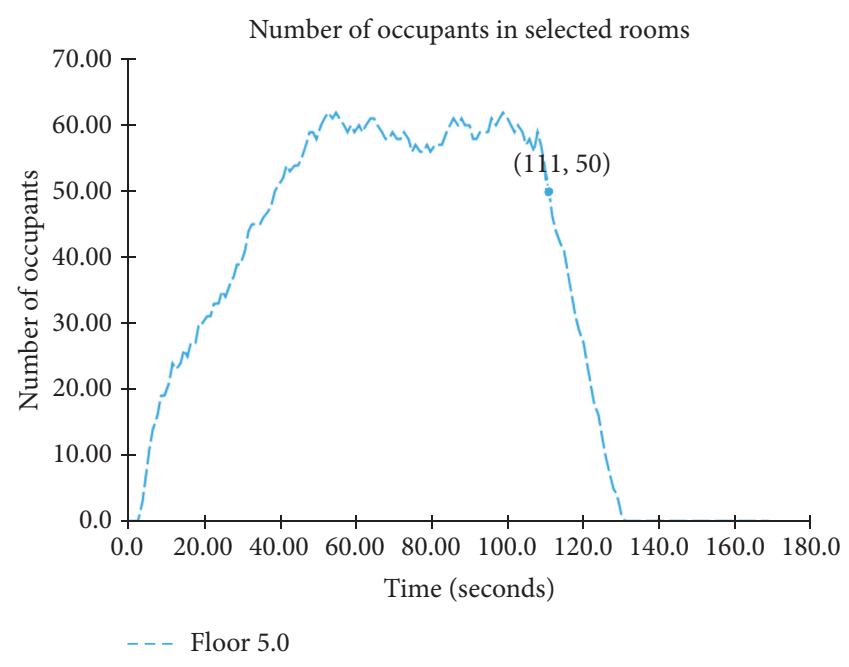

(b) Disorderly evacuation

FIgURE 3: The different progress curves of evacuation.

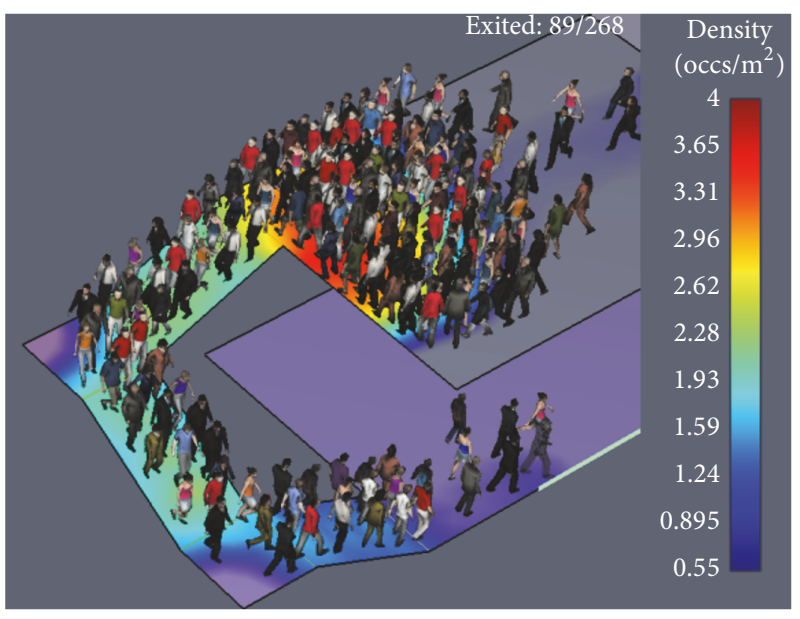

(a) Disorderly evacuation

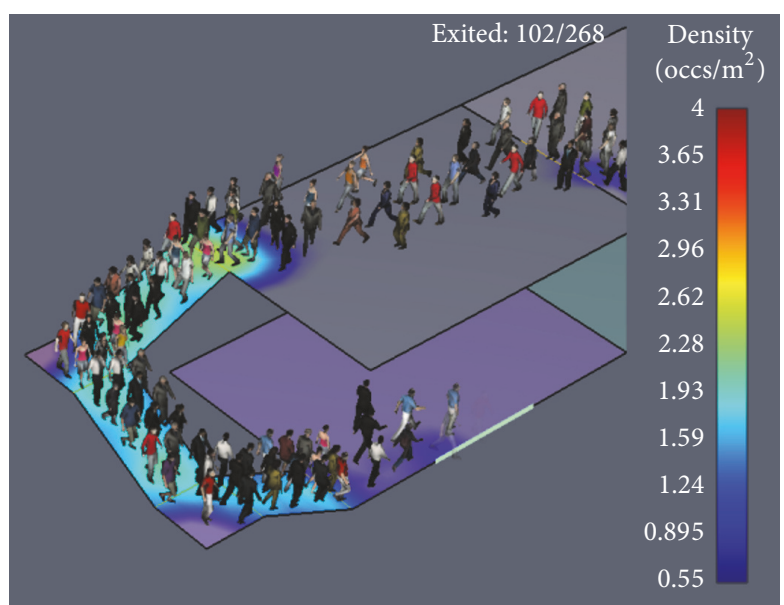

(b) Orderly evacuation

Figure 4: Two kinds of evacuation state.

positive contribution to the reduction of the evacuation time. We think the reason may be that the propulsive force of the arching effect makes occupants walk down the stairs faster. However, the density in disorderly evacuation is close to the critical value of trampling, but orderly evacuation kept the occupants density in the low level all the time. At last, we had faith in the possibility of reduction of trampling in orderly evacuation.

This paper studied evacuation strategy preliminarily. We are going to take the influence of various factors into account in the future, such as the cluster effect, the diversity of individual behavior, and physical characteristics.

\section{Disclosure}

The views expressed herein are those of the authors and have not been reviewed or approved by the granting agency.

\section{Conflicts of Interest}

The authors declare that they have no conflicts of interest.

\section{Acknowledgments}

The research reported in this article was supported by grants from Hubei Key Laboratory of Construction and Management in Hydropower Engineering of China Three Gorges University (2016KSD06 and 2016KSD13) and National Natural Science Fund (51609128, 51509143, and 51379110).

\section{References}

[1] T. L. Graham and D. J. Roberts, "Qualitative overview of some important factors affecting the egress of people in hotel fires," International Journal of Hospitality Management, vol. 19, no. 1, pp. 79-87, 2000. 
[2] D. Helbing, I. Farkas, and T. Vicsek, "Simulating dynamical features of escape panic," Nature, vol. 407, no. 6803, pp. 487490, 2000.

[3] D. Helbing, "Social force model for pedestrian dynamics," Physical Review E Statistical Physics Plasmas Fluids and Related Interdisciplinary Topics, vol. 51, no. 5, pp. 4282-4286, 1995.

[4] D. R. Parisi and C. O. Dorso, "Microscopic dynamics of pedestrian evacuation," Physica A: Statistical Mechanics and its Applications, vol. 354, no. 1-4, pp. 606-618, 2005.

[5] A. Kirchner and A. Schadschneider, "Simulation of evacuation processes using a bionics-inspired cellular automaton model for pedestrian dynamics," Physica A: Statistical Mechanics and its Applications, vol. 312, no. 1-2, pp. 260-276, 2002.

[6] M. Muramatsu, T. Irie, and T. Nagatani, "Jamming transition in pedestrian counter flow," Physica A: Statistical Mechanics and its Applications, vol. 267, no. 3-4, pp. 487-498, 1999.

[7] D. Zhao, L. Yang, and J. Li, "Occupants' behavior of going with the crowd based on cellular automata occupant evacuation model," Physica A: Statistical Mechanics and its Applications, vol. 387, no. 14, pp. 3708-3718, 2008.

[8] A. Kirchner, K. Nishinari, and A. Schadschneider, "Friction effects and clogging in a cellular automaton model for pedestrian dynamics," Physical Review E: Statistical, Nonlinear, and Soft Matter Physics, vol. 67, no. 5, Article ID 056122, 2002.

[9] S. Liu, L. Yang, T. Fang, and J. Li, "Evacuation from a classroom considering the occupant density around exits," Physica A: Statistical Mechanics and its Applications, vol. 388, no. 9, pp. 1921-1928, 2009.

[10] S. P. Hoogendoorn and P. H. L. Bovy, "Pedestrian route-choice and activity scheduling theory and models," Transportation Research Part B: Methodological, vol. 38, no. 2, pp. 169-190, 2004.

[11] J. D. Sime, "An occupant response shelter escape time (ORSET) model," Safety Science, vol. 38, no. 2, pp. 109-125, 2001.

[12] K. Fridolf, D. Nilsson, and H. Frantzich, "Fire evacuation in underground transportation systems: a review of accidents and empirical research," Fire Technology, vol. 49, no. 2, pp. 451-475, 2013.

[13] P. Tofilo, M. Cisek, and K. Lacki, The Study on the Effects of the Counter-Flow on the Evacuation of People from Tall Buildings, Springer International Publishing, Cham, Switzerland, 2014.

[14] A. B. A. M. Rangel-Huerta, "Multiagent system applied to the modeling and simulation of pedestrian traffic in counterflow," Journal of Artificial Societies and Social Simulation, vol. 14, no. 3, article 2, 2011.

[15] M. Isobe, T. Adachi, and T. Nagatani, "Experiment and simulation of pedestrian counter flow," Physica A: Statistical Mechanics and its Applications, vol. 336, no. 3-4, pp. 638-650, 2004.

[16] I. Cłapa, M. Cisek, P. Tofiło, and M. Dziubiński, "Firefighters ascending and evacuation speeds during counter flow on staircase," Safety Science, vol. 78, pp. 35-40, 2015.

[17] M. Delin, J. Norén, E. Ronchi, K. Kuklane, A. Halder, and K. Fridolf, "Ascending stair evacuation: walking speed as a function of height," Fire and Materials, 2016.

[18] J. J. Fruin, “Designing for pedestrians,” Moving Sidewalks, 1970.

[19] R.-Y. Guo, H.-J. Huang, and S. C. Wong, "Route choice in pedestrian evacuation under conditions of good and zero visibility: experimental and simulation results," Transportation Research Part B: Methodological, vol. 46, no. 6, pp. 669-686, 2012.

[20] R. S. C. Lee and R. L. Hughes, "Exploring trampling and crushing in a crowd," Journal of Transportation Engineering, vol. 131, no. 8, pp. 575-582, 2005.
[21] D. Papakonstantinou and A. Benardos, "Analysis of the crowd evacuation modeling approaches for the case of urban underground spaces," Procedia Engineering, vol. 165, pp. 602-609, 2016. 


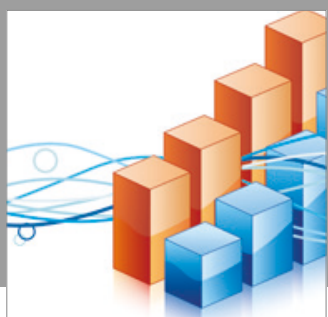

Advances in

Operations Research

vatersals

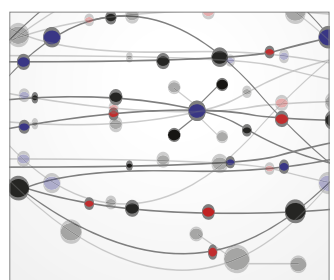

\section{The Scientific} World Journal
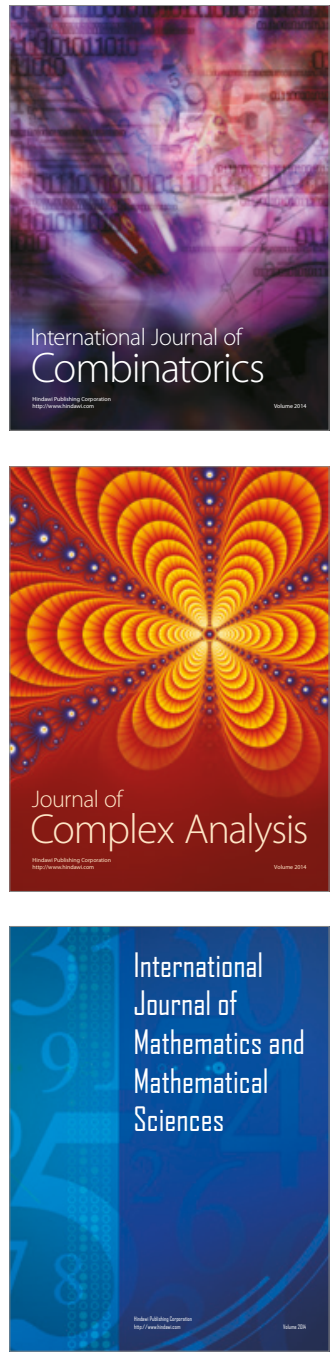
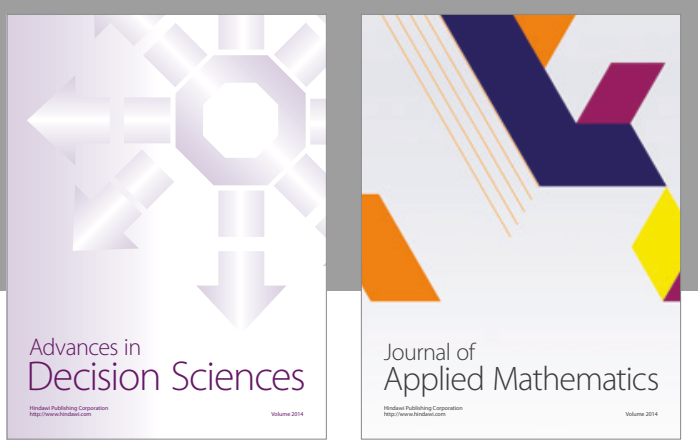

Algebra

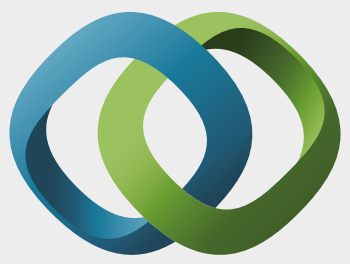

\section{Hindawi}

Submit your manuscripts at

https://www.hindawi.com
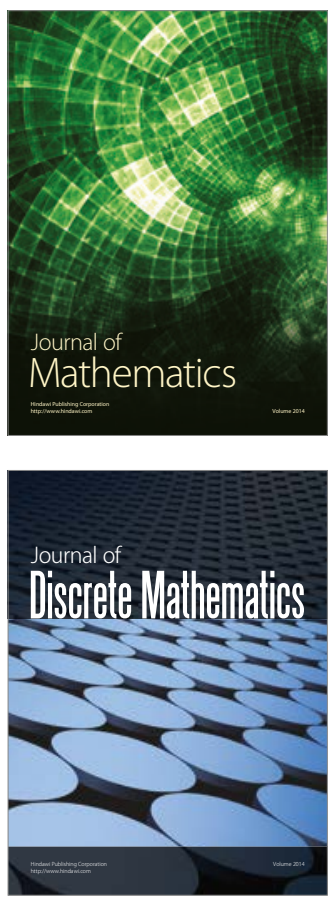

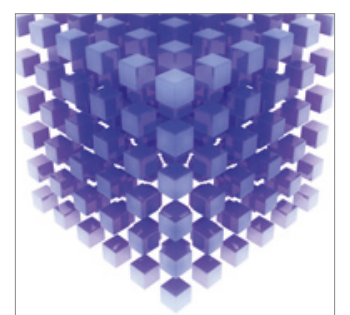

Mathematical Problems in Engineering
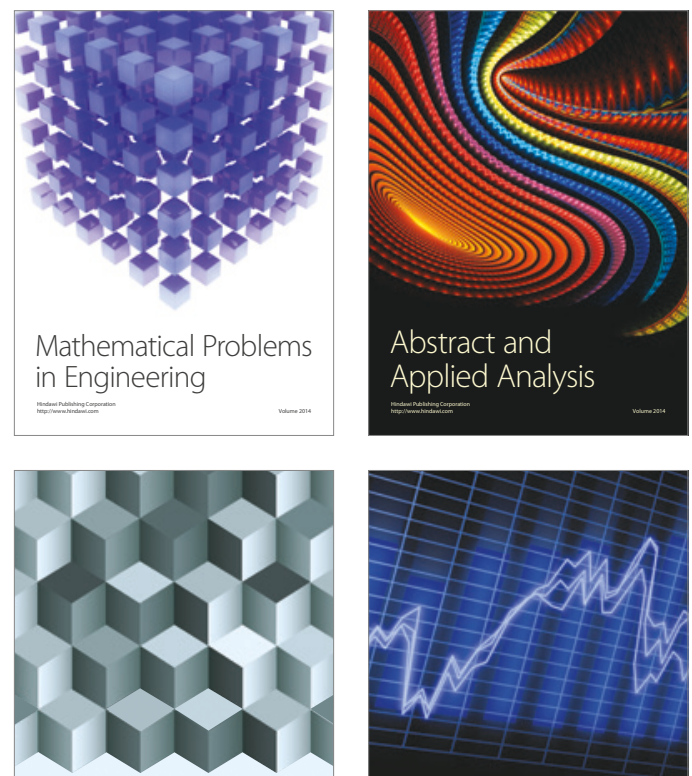

Journal of

Function Spaces

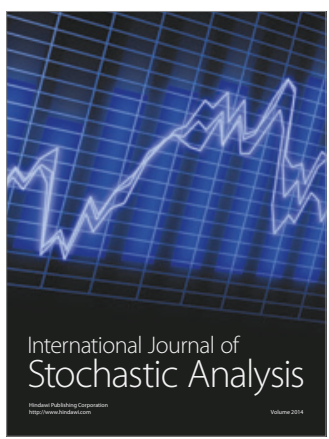

Probability and Statistics
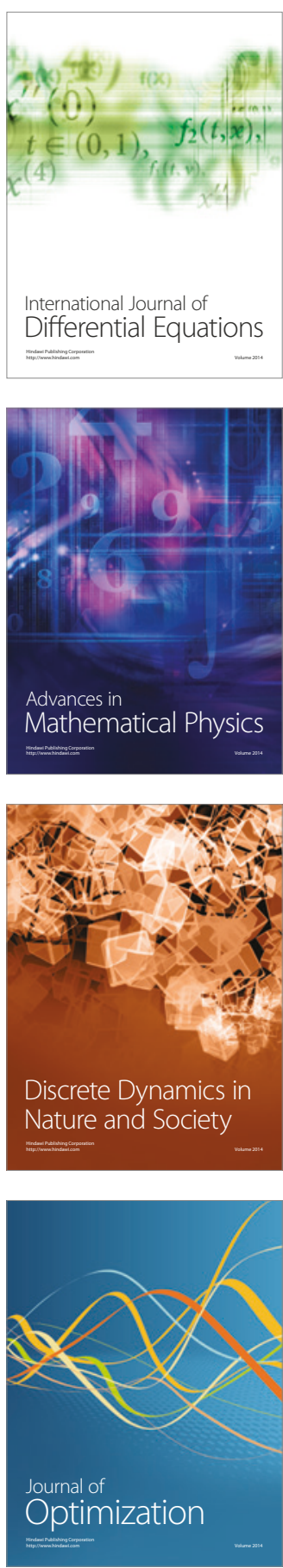